\title{
The rise in stunting in relation to avian influenza and food consumption patterns in Lower Egypt in comparison to Upper Egypt: results from 2005 and 2008 Demographic and Health Surveys
}

Justine A Kavle ${ }^{1,2^{*}}$, Fatma El-Zanaty ${ }^{3}$, Megan Landry ${ }^{4}$ and Rae Galloway ${ }^{1,2}$

\begin{abstract}
Background: A 2006 avian influenza (Al) outbreak resulted in mass removal of chickens in Lower Egypt, which decreased the household supply of poultry. Poultry, a key animal-source food, contains nutrients critical for child growth. This paper examines determinants of stunting between 2006 and 2008 in children 6 to 59 months of age within the context of the Al outbreak.

Methods: The 2005 and 2008 nationally representative Egypt Demographic and Health Surveys (EDHS) were used to analyse anthropometric data from 7,794 children in 2005 and 6,091 children in 2008. Children, 6-59 months of age, with length for age Z-score $<-2$ S.D. were categorized as stunted. Predictors of stunting were examined by bivariate and multivariable analyses, focusing on Lower Egypt, where a rise in stunting occurred, and Upper Egypt, where stunting declined.
\end{abstract}

Results: Between 2005 and 2008, Upper Egypt experienced a significant decline in stunting (28.8 to 21.8\%, P<0.001). Lower Egypt experienced a significant rise in stunting ( 16.6 to 31.5\%, $\mathrm{P}<0.001)$, coinciding with the $2006 \mathrm{Al}$ outbreak. In Lower Egypt (2008), households owning poultry were $41.7 \%$ less likely to have a stunted child [aOR $0.58 ; 95 \% \mathrm{Cl}$ $(0.42,0.81) \mathrm{P}=0.002]$, and $12-47$ month old children were $2.12-2.34$ times [ $95 \% \mathrm{Cl}(1.39-3.63) \mathrm{P} \leq 0.001$ ] more likely to be stunted than 6-11 month old children. Older children were likely affected by Al, as these children were either in-utero or toddlers in 2006. In Upper Egypt, stunting peaked at 12-23 months [aOR 2.62, 95\% Cl (1.73-3.96), $\mathrm{P}<0.001$ ], with lowered risk (22-32\%) of stunting in 24-47 month old children [aOR1.65, 95\% 1.07-2.53, $\mathrm{P}=0.022,24-35$ month old] and [aOR 1.57, 95\% Cl 1.01-2.43, $\mathrm{P}=0.04336-47$ months old]. A two-fold increase in child consumption of sugary foods between 2005 and 2008 was found in Lower Egypt (24.5\% versus 52.7\%; $P<.001$ ).

Conclusions: Decreased dietary diversity, reduced poultry consumption, substitution of nutritious foods with sugary foods paralleled a reduction in household raising of birds, following the Al outbreak in Lower Egypt and not Upper Egypt. Increased feeding of sugary foods due to fear of illness or greater penetration of these foods may be related to stunting. Advice on infant and young child feeding is needed to improve dietary intake and reduce sugary food consumption.

Keywords: Avian influenza, Stunting, Dietary diversity, Maternal nutrition, Infant and young child nutrition, Sugar

\footnotetext{
* Correspondence: jkavle@path.org

${ }^{1}$ Maternal and Child Health Integrated Program (MCHIP), 1776 Massachusetts

Ave NW, Suite 300, Washington DC, USA

2PATH, Maternal, Child Health and Nutrition (MCHN), 455 Massachusetts Ave NW, Suite 1000, Washington DC 20001, USA

Full list of author information is available at the end of the article
}

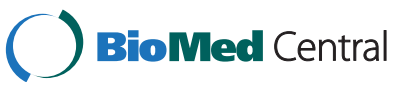

(c) 2015 Kavle et al.; licensee BioMed Central. This is an Open Access article distributed under the terms of the Creative Commons Attribution License (http://creativecommons.org/licenses/by/4.0), which permits unrestricted use, distribution, and reproduction in any medium, provided the original work is properly credited. The Creative Commons Public Domain Dedication waiver (http://creativecommons.org/publicdomain/zero/1.0/) applies to the data made available in this article, unless otherwise stated. 


\section{Background}

Poor growth in height/length occurs when a child is not growing according to his/her potential. A stunted child is considered too short for his/her age when height for age is below minus two standard deviations (-2 SD) from the median of the reference population, using WHO Child Growth Standards [1]. Stunting or chronic malnutrition is a process caused by inadequate food intake and infection during the period that begins in utero and through the child's first two years of life-known as the "first 1000 days" and referred to as " the window of opportunity to prevent malnutrition" [2]. Stunted children often become stunted adults who have reduced work productivity, and life-time wage earnings in comparison to their non-stunted counterparts [3,4]. Malnutrition results in losses in gross domestic product of up to two to three percent [4].

Egypt faces ' the double burden of malnutrition', which is characterized by static prevalence of stunting, accompanied by rising overweight and obesity in both adults and children [5-7]. One of every three Egyptian children under 5 years old is stunted, ranking Egypt among the 34 countries globally where $90 \%$ of the stunted children reside [6,7]. The total economic cost of child undernutrition in Egypt is estimated at 20.3 billion Egyptian pounds (3.7 billion U.S. dollars), or $1.9 \%$ of the GDP. This economic burden is primarily due to stunting-related labor productivity losses, affecting $64 \%$ of Egyptians [8]. In addition, twenty percent of children under the age of five are overweight or obese [5], which also have associated economic losses, due to chronic diseases, estimated to be US $\$ 1.3$ billion by 2015 [9].

Multiple factors influence malnutrition, including micronutrient deficiencies, decreased consumption of animal source foods, and social factors that impact livelihood production and income purchasing power $[10,11]$. Raising animals, such as poultry and livestock, has been shown to have a positive impact on nutritional status, as well as significantly contribute to household income and expenditure $[12,13]$.

Since 2005, Egypt has faced rising poverty rates and food and fuel prices resulting in reduced household access to nutrient rich animal source foods [14]. Furthermore, in 2006, an avian influenza (AI) outbreak resulted in mass removal of chickens in Lower Egypt, where the majority of families raise, consume and sell poultry [15]. In response to fears of human transmission of the infection, and to protect the health of the population, countries that have experienced similar epidemics have also taken measures to remove these foods from food supplies [10]. Such actions can affect livelihoods, which are often reliant on village poultry production, as a source of food and income [13].

Therefore, by removing chickens, as sources of household income and food for the family diet, an AI outbreak can exacerbate rising household expenditures and decrease access to animal source foods [16]. In Egypt, the AI outbreak has contributed to diminished disposable income, reduced availability of supplies of poultry as food for the family, and reductions in quality of the diet, all of which may leave children vulnerable to malnutrition (see Figure 1) [17].

Nutrients, such as vitamin A, zinc and iron, found in poultry, meat and other animal source foods are critical for attaining optimal growth $[11,18,19]$. Studies have shown that consumption of animal source foods is predictive of positive gains in child growth, specifically height and weight $[11,20]$. A recent study by Iannotti and Roy demonstrated that when consumption of poultry meat is reduced, due to an AI outbreak, child stunting prevalence increased by 3.9 percentage points and children are more likely to succumb to poorer growth outcomes, with lower length for age and weight for age across the population [21].

A large rise in stunting (19\% to $36 \%$ ) among children younger than 5 years of age occurred in Lower Egypt between the 2005 and 2008 Egypt Demographic and Health surveys (EDHS) [6], which coincided with the timing of the AI outbreak. In contrast, stunting decreased in Upper Egypt during this same time period [6], despite higher poverty rates in Upper Egypt (47.5\%) compared with Lower Egypt (11.3\%) [22]. Yet, despite the devastating effects of AI as a disease, there is limited research on factors associated with the AI outbreak, on the rise in stunting observed between the 2005 and 2008 EDHS years - pre and post- AI outbreak in Egypt. We hypothesize that the AI outbreak, and subsequent removal of chickens, led to reduced consumption of poultry, which influenced the rise in stunting in Lower Egypt.

To date, no studies have examined factors and events that may have contributed to the simultaneous rise or decrease in stunting in Lower Egypt and Upper Egypt, respectively. The objective of this paper is to examine changes in stunting in children 6 to 59 months of age, and to investigate the relationship between stunting and AI outbreak and nutrition-related variables in Lower and Upper Egypt, using 2005 and 2008 EDHS data.

\section{Conceptual framework}

This study was conceived and based on an adaptation of the World Health Organization (WHO) Framework on Childhood Stunting (Figure 1). The framework describes the linkages between household and family factors, including maternal dietary practices, infection, infant and young child feeding, and stunting [3]. The WHO model also provides a way to explore underlying factors affecting stunting, with consideration of community and societal factors and socioeconomic factors. Reductions in supply, availability, and consumption of poultry and eggs are also featured. 


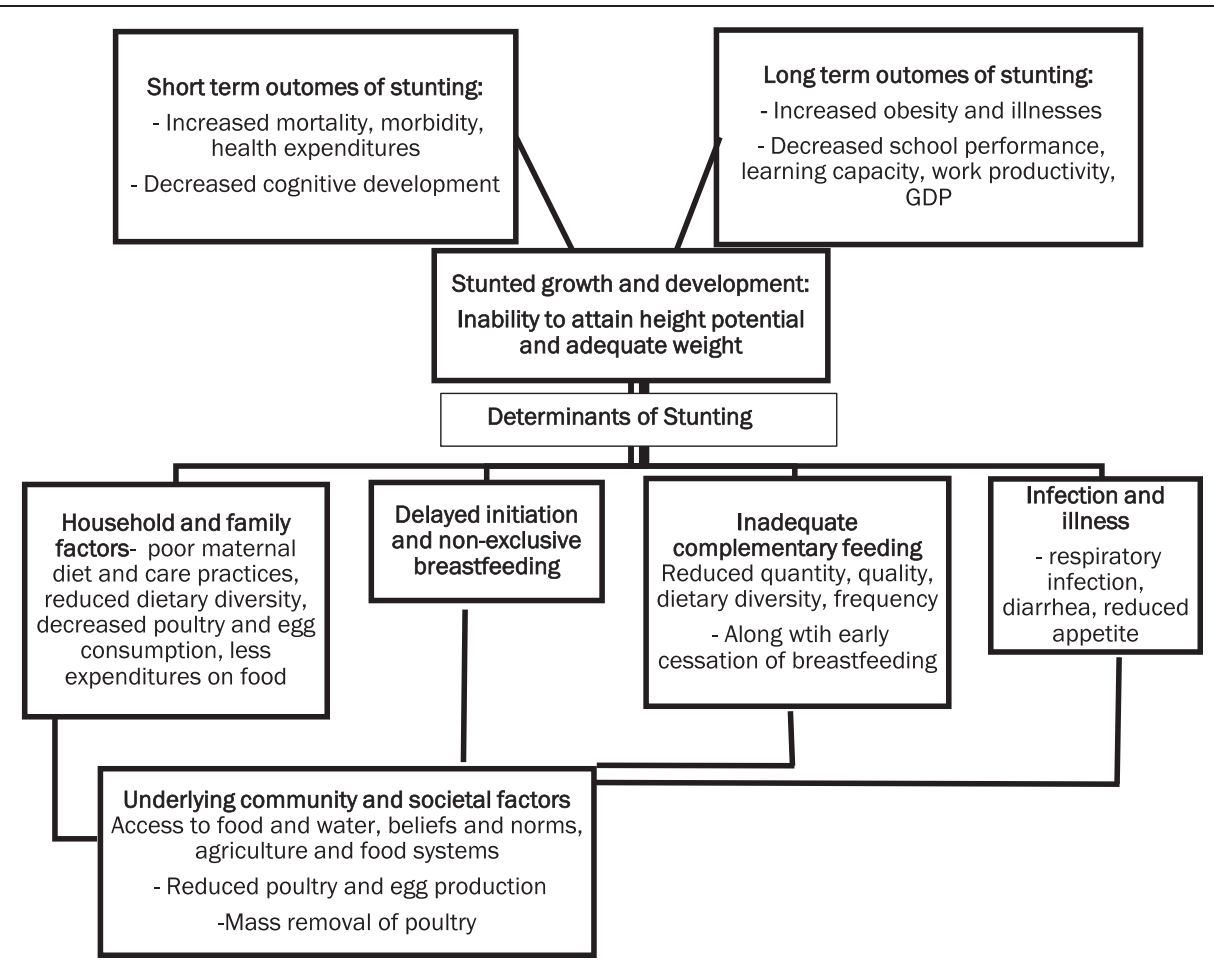

Figure 1 Conceptual Framework for the relationship between avian influenza, nutrition factors, and stunting in Lower Egypt. Legend: Adapted from World Health Organization (WHO) Framework on Stunting [3].

\section{Methods}

The paper uses data from the child recode and supplemental survey files of the 2005 and 2008 EDHS, nationally representative cross-sectional surveys conducted in Egypt. Permission of use of these publicly available data was requested online from the Demographic and Health Survey (DHS) Program website (http://dhsprogram.com/ Data/) and approval was obtained to download the data. The Stata data files for child recode and a special issues survey module on AI for 2008, were downloaded for the analyses presented here. The EDHS surveys were approved by the Egypt Ministry of Health and ICF Macro (previously known as ORC Macro, in 2005) Institutional Review board in Calverton, Maryland, USA.

\section{Sample size}

The 2005 and 2008 EDHS used three-stage probability sampling that consisted of selection of primary sampling units (PSUs) from lists of shiakhas/towns and villages, with geographic stratification by and within each region and by urban-rural residence.

Egypt is divided into 27 administrative units, known as governorates. Each governorate is divided into shiakhas (urban areas), villages (rural areas) and medinas (major towns).

Prior to PSU selection for the 2005 and 2008 EDHS, the lists of shiakhas, medinas, and villages were grouped by governorate, and then stratified by geographic location within each governorate. Survey data collection occurred during approximately the same seasonal timeframes from March - July 2005 for the 2005 EDHS and February- June 2008 for the 2008 EDHS.

Shiakhas and villages were defined as primary sample units. During the first-stage selection, a total of 610 PSUs (275 shiakhas and 335 villages) were chosen for the 2008 EDHS sample and a total of 682 PSUs (289 shiakhas and 393 villages) were selected for the 2005 EDHS. In the second stage, each of the PSUs was divided into a number of parts of roughly equal size (assuming approximately 5,000 persons per part) using maps in both survey years.

In 2008, in very large shiakhas or villages (defined as a population of approximately 100,000 and more), three parts were selected from each PSU. In shiakhas or villages with 20,000-99,999 population, two parts were selected and one part per PSU was selected for remaining smaller shiakhas and villages. In each PSU, a quick count was carried out in the selected parts for division into segments of roughly equal size. A total of 1,287 segments were chosen from the parts in each shiakha and village (three segments from 48 PSUs, two segments from 561 PSUs, and one segment from one PSU).

In 2005, in large shiakhas or villages (approximately 20,000 and more population), two parts were chosen 
from each PSU. In smaller shiakhas and villages, one part was selected. A quick count was conducted to divide selected parts into a number of segments of roughly equal size. After the quick count was completed, two segments were then selected from each PSU. In large shiakhas and villages one segment was chosen from each of two parts. In small shiakhas and villages two segments were chosen from the sole selected part.

In 2005 and 2008, a systematic sampling of households, using household lists from each segment, was carried out from four regions of Egypt (Urban governorates, Lower Egypt, Upper Egypt, and Frontier Governorates). Over sampling was conducted in remote areas to derive population level estimates. Details on clustering and sample selection are explained further in published reports $[6,23]$.

The EDHS is not self-weighted at the national level, thus weights were calculated to account for the proportional difference between the number of households contained in the survey samples and the size of the population in each governorate. Weights were then applied to the multivariable models to obtain the national level estimates.

These analyses were focused on Lower Egypt, where a rise in stunting was documented between the 2005 and 2008 EDHS, with comparisons to Upper Egypt, where little change occurred between the 2005 and 2008 EDHS, as well as to other regions of Egypt, where appropriate. In the 2005 EDHS survey, 21,972 sample households (6,454 households in Lower Egypt and 9,723 in Upper Egypt) were selected for interviews and nearly all ever-married women ages 15-49 were interviewed (99\% response rate) in those households. In the 2008 EDHS survey, 18,968 sample households (7,303 households in Lower Egypt and 7,310 households in Upper Egypt) were selected for interviews and nearly all ever-married women ages 15-49 were interviewed (98.8\% response rate). The nutritional status of children was determined by measuring the height/length and weight of all children less than six years of age living in households selected in the EDHS sample, where $99 \%$ of children were measured. Six (2005) and ten percent (2008) of the data were considered implausible due to outliers or no data for child age in months was available. Thus, the data were restricted to 12,131 and 9,103 children, 6-59 months of age, in 2005 and 2008, respectively, with credible anthropometric data and to children that were breastfed, which included the majority of the sample (97.2\%). We further restricted our analyses to 7,794 children in 2005 and 6,091 children in 2008 that were lastborn children between the ages of 6 to 59 months with credible anthropometric data. Of those, 2,292 resided in Lower Egypt in 2005 and 2,293 in 2008, while 3,893 resided in Upper Egypt in 2005 and 2,708 in 2008. The remaining children resided in Frontier or Urban
Governorates (less than 10\% in either region in 2005 or 2008). In examining dietary consumption in the previous 24 hours, descriptive data included 2,759 children in 2005 and 2,392 children in 2008 between the ages 6 to 23 months with both infant and young child feeding (IYCF) and anthropometric information. This is the age group from which information on dietary consumption is collected in the EDHS.

\section{Assessment of child nutritional status}

Recumbent length of children 6-59 months was measured lying down on a board produced for survey settings. Child weight was measured using UNICEF SECA scales (SECA Model 872). To measure the weight of children that cannot stand on their own, maternal weight was measured first, the scale tared to 0 and then child weight was calculated. In the following analyses, the WHO Multicenter Growth Reference Study Standards [24] were used to ascertain nutritional status for both EDHS 2005 and 2008 datasets. Stunting was calculated, as an indicator of physical growth from anthropometric measurements: children with Length for Age $\mathrm{Z}$ score $(\mathrm{LAZ})<-2$ were categorized as stunted.

\section{Study instruments}

Two different EDHS questionnaires were used in this analysis: (i) the women's questionnaire; and (ii) a supplemental special health issues questionnaire. The women's questionnaire included background information such as education, residence status, birth intervals, parity, antenatal care, child illness, size at birth, infant and young child feeding, mother's food consumption. A household wealth index, as a proxy for family income, was created from the household questionnaire using housing characteristics, etc. (described in detail below).

In the 2005 and 2008 EDHS, mothers who had at least one child under two years of age living with them were asked about the types of foods and liquids they and their youngest child had consumed during a twenty-four hour period prior to the survey. Mothers were also asked about the number of times the child had eaten any solid or semi-solid foods during this same time period.

The 2008 EDHS also included a special AI module as part of the "special health issues interviews." During the household interviews, data were collected on the extent of household ownership of poultry and other birds and on the ways in which poultry and birds were handled within households. The question domains included: awareness of AI; awareness of AI symptoms in poultry/ birds; awareness of AI symptoms among humans; awareness of modes of transmission and prevention; and attitudes towards AI. A detailed description of variables are described below. 


\section{Description of variables Outcome variable}

This study used stunting among children 6-59 months of age as an outcome variable. The analysis categorized stunting as a dichotomous variable stunted $=1$; and Not stunted $=0$.

\section{Independent variables}

Child-, maternal- and socioeconomic factors considered in this study are covariates that were either identified in recent analyses of EDHS data [25], factors deemed to have a potential association with stunting based on previous literature or known associations, including dietary related factors and morbidity collected during the 2005 and 2008 EDHS surveys. Because AI was associated with stunting in previous analyses of EDHS 2008 data these variables were further explored in this analysis [25].

A list of explanatory variables with definitions and defined categories are presented in Table 1. Six variables were included for maternal level factors, including: age; education; body mass index (BMI), categorized as thin $\left(<18.5 \mathrm{~kg} / \mathrm{m}^{2}\right)$, normal $\left(18.5\right.$ to $\left.24.9 \mathrm{~kg} / \mathrm{m}^{2}\right)$, overweight (from 25 to $\left.29.9 \mathrm{~km} / \mathrm{g}^{2}\right)$, or obese $\left(\geq 30 \mathrm{~kg} / \mathrm{m}^{2}\right)$; birth interval ( $<24$ months, 24-47 months, first born or $48+$ months between birth and previous pregnancy); perception of size at birth (very small, small, and average or larger) and; consumption of food groups.

Socioeconomic level variables included household wealth index and place of residence (urban or rural). Household wealth index, a proxy for household income, is comprised of the following assets: electricity, radio, $\mathrm{TV}$, fridge, bicycle, motorcycle, car, phone, and type of the flooring material. The index uses principal components to build single indicators for wealth based on all the variables in DHS data that measure aspects of wealth [26]. DHS routinely provides these wealth indicators in their data sets for a number of countries. The wealth index was included in the recode for the 2005 and 2008 EDHS surveys. Further details of how the wealth indices were used for EDHS can be found elsewhere [27]. Water and sanitation variables included drinking water source and type of toilet facility. An additional file with tables shows these results in more detail [see Additional file 1].

Child age group and child sex were included for child level variables. Variables related to maternal nutrition and infant and child feeding, which were explored in these analyses, included breastfeeding initiation and duration; minimum dietary diversity for breastfed children; minimum meal frequency for breastfed children; number of food groups consumed for mothers and children; child and maternal consumption of specific sources of foods (meat, egg, fish consumption, as well as foods made with oil, fat, butter, and sugary foods) and; illness experienced (diarrhea or acute respiratory infection).
These data are restricted to breastfed children, as nonbreastfed children only comprised $2.82 \%$ of the sample population. Data on sugary food consumption was only available at the child level and is therefore not reported for maternal level consumption. Minimum dietary diversity is defined as consumption of at least four of seven food groups during the previous 24 hours by a child 623 months of age. Food groups included: 1) grains, roots and tubers; 2) legumes and nuts; 3 ) dairy products (milk, yogurt, cheese); 4) flesh foods (meat, fish, poultry and liver/organ meats); 5) eggs; 6) vitamin-A rich fruits and vegetables; and 7) other fruits and vegetables. Minimum meal frequency, a proxy for energy intake from foods apart from breastmilk, is defined as children given solid or semi-solid foods two times per day for breastfed infants 6-8 months, and three times per day for breastfed children 9-23 months.

\section{Statistical data analyses}

We sought to examine factors associated with stunting from both EDHS surveys to determine the strength of the association of each characteristic in relation to the likelihood of stunting in 2005 and 2008, in Lower Egypt. The outcome variable for the final logistic regression models is presence or absence of stunting $(\mathrm{Y}=1=$ stunted, $0=$ not stunted). Stunting is defined as children below $-2.0 \mathrm{Z}$ scores for $\mathrm{LAZ}$ ) in relation to the WHO international growth standards [24].

Univariate analyses were used to examine distributions and normality of continuous predictor variables such as maternal age and household size, while frequencies and percentages were used to examine potential predictor and confounding categorical variables, such as sex of child, educational level of mother, maternal BMI, rural residence, birth intervals, and birth size. Bivariate analyses were performed using Pearson's chi-square, to test differences in frequencies of categorical variables and $t$-tests, for differences in means of continuous variables. Variables found to be significant at the $p<0.10$ were included in the final multivariable analysis models. Child level and maternal dietary variables explored were not found to be significant and excluded from final models. Descriptive and bivariate associations of dietary variables and stunting analyses are discussed in these analyses.

Predictors of stunting in Lower Egypt were assessed using multivariable logistic regression models and statistical significance was set at the probability of a type-one error $p<0.10$. All variables in the final logistic regression model were tested for multicollinearity using the variance inflation factor test. Variance inflation factor values greater than five were considered to be collinear and were removed from the final model [28]. Maternal educational level and household wealth were specifically checked for multicollinearity (i.e. given wealth often increases with 
Table 1 Description of variables used in analysis

\section{Variables \\ Child level nutrition-related factors}

Age

Gender

Diarrhea

Short, rapid breathing with cough

Consumption of food groups/ specific foods*

\section{Description and defined categories}

$0=6$ to 11 months

$1=12$ to 23 months

0 = female $1=$ male

$0=$ Child did not have diarrhea in the last 2 weeks

$1=$ Child had diarrhea in the last 2 weeks

$0=$ Child did not experience short, rapid breaths with a cough

$1=$ Child experienced short, rapid breaths with a cough

$1=$ Grains, roots and tubers

$2=$ Legumes and nuts

3 = Dairy products

4 - Meat, poultry, fish, shellfish and organ meats

$5=$ Eggs

$6=$ Vitamin A rich fruits and vegetables

$7=$ Other fruits and vegetables

$8=$ Sugary foods*

Maternal level nutrition-related factors

Education

$0=$ No Education

$1=$ Primary Education

$2=$ Secondary Education

$3=$ Higher

Age

Body Mass Index (BMI)

Mother's age in years

$1=$ Thin/Normal $\left(<25 \mathrm{~kg} / \mathrm{m}^{2}\right)$

2 = Overweight (25 to $30 \mathrm{~km} / \mathrm{g}^{2}$ )

$3=$ Obese $\left(>30 \mathrm{~kg} / \mathrm{m}^{2}\right)$

Consumption of food groups

$1=$ Grains, roots and tubers

$2=$ Legumes and nuts

$3=$ Dairy products

4 - Meat, poultry, fish, shellfish and organ meats

$5=$ Eggs

$6=$ Vitamin A rich fruits and vegetables

$7=$ Other fruits and vegetables

$<24$ months, 24-47 months, first born or 48+

Subjective assessment by the mother: ( $1=$ very small, $2=$ smaller than average, $3=$ average or larger)

$$
\begin{aligned}
& 1=\text { Urban } 2=\text { Rural } \\
& 1=\text { Poorest } \\
& 2=\text { Poor } \\
& 3=\text { Middle } \\
& 4=\text { Richer } \\
& 5=\text { Richest }
\end{aligned}
$$


education), and these variables were not found to be collinear. All analyses were adjusted for survey design and conducted in Stata version 12.0 (Stata Corporation, College Station, TX). We employed Stata survey commands in our regression analyses to account for the multi-stage survey design and to examine the influence of survey sampling weights in our models. We present weighted data in our models.

\section{Results}

\section{Description of changes in stunting between 2005 and 2008 EDHS}

Overall, in Egypt stunting rates among 6-59 month old children increased slightly between 2005 and 2008 EDHS (22.6\% versus $25.4 \% ; \mathrm{P}<0.001)$. However, variation in stunting differed by region and by survey year, shown in Figure 2. All regions experienced significant changes between 2005 and 2008. Upper Egypt had a significant decline in stunting from $28.8 \%$ to $21.8 \%(\mathrm{P}<0.001)$ from 2005 to 2008. Lower Egypt experienced a significant rise in stunting from $16.6 \%$ to $31.5 \%$ ( $\mathrm{P}<0.001)$ during the same period, coinciding with the 2006 AI outbreak. Frontier and Urban Governorates also had significant increases in stunting levels between the two survey years (16 to $20.5 \%$, Urban; 15.9 to $25.2 \%$, Frontier $\mathrm{P}<0.05$ ).

\section{Description of demographic, nutrition and Al related characteristics and stunting}

Tables 2 and 3 show the proportion of stunting in children 6-59 months in Lower Egypt and Upper Egypt by maternal and child level socio-demographic, health and nutrition characteristics from 2005 and 2008 EDHS surveys, in bivariate analyses.

Child age was significantly associated with stunting in both survey years and regions of Egypt. In Upper Egypt, stunting peaked at 12-23 months of age in both survey years (33.1\% in 2005 and $28 \%$ in 2008). In comparison, in Lower Egypt, stunting peaked at 6-11 months, with similar levels at 12-23 months and 24-35 months in 2005. Yet, in 2008, higher, sustained levels of stunting were shown in Lower Egypt children 12-47 months of age, with stunting peaking at 36-47 months of age (37.7\%). In Lower Egypt, a significantly greater proportion of males were stunted (34.4\%) than females in 2008 $(\mathrm{p}=0.002)$ than $2005(17.1 \%) \quad(\mathrm{p}=0.510)$. In Upper Egypt, males were more likely to be stunted than females in 2005, but not 2008. (Table 2 and Table 3). Residence was not associated with stunting in Lower Egypt, while stunted children were more likely to reside in rural areas in Upper Egypt in both survey years.

The mean age for mothers of children 6-59 months of age was approximately 29 years old for both regions and survey years. Maternal education was not associated with stunting in Lower Egypt for either survey year with prevalence of stunting being similar across educational levels (Table 2). In Upper Egypt, a significant association between maternal education and stunting was shown in both survey years, with stunting decreasing as mothers' educational levels increased (Table 3). Women with higher education were the least likely to have a stunted child. Stunting by household wealth was evenly distributed across wealth quintiles in Lower Egypt in 2005, except for the richest quintile, which had the highest proportion of stunting $(\mathrm{p}=0.044)$. In 2008, the stunting was lowest in the poorest wealth quintile compared to the middle to richest wealth quintiles. In Upper Egypt, household wealth was associated with stunting for both survey years, revealing higher proportion of stunting among poorer wealth quintiles. In Lower and Upper Egypt, in 2005, stunted children were more likely to have a mother that was thin, normal or overweight than obese ( $\mathrm{p}<0.001)$. Yet, in 2008, stunting by maternal BMI was

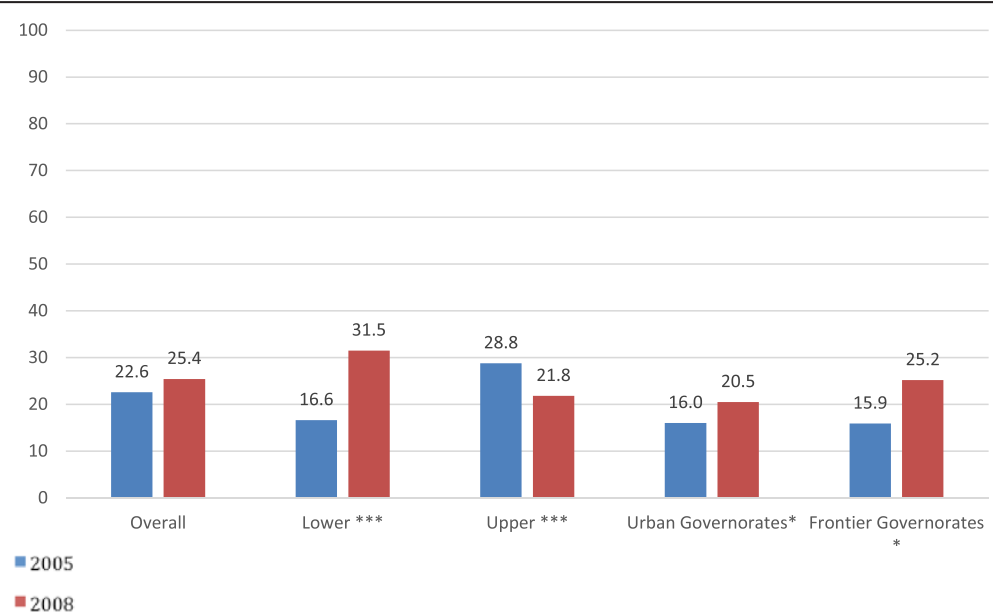

Figure 2 Proportion of stunted children, 6-59 months of age, by region, Egypt 2005 and 2008. Legend: ${ }^{*} P<0.05$ (Child); ${ }^{* * P}<0.001$ (Child). 
Table 2 Proportion of stunting, 6-59 months, Lower Egypt $2005(\mathrm{~N}=2292)$ and $2008(\mathrm{~N}=2293)$

\begin{tabular}{|c|c|c|c|c|c|c|}
\hline \multirow[t]{2}{*}{ Factor } & \multicolumn{3}{|l|}{2005} & \multicolumn{3}{|l|}{2008} \\
\hline & Total N [\%] & $\begin{array}{l}\text { Stunting, 6-59 } \\
\text { months n [\%] }\end{array}$ & p-value & Total N [\%] & $\begin{array}{l}\text { Stunting, 6-59 } \\
\text { months n [\%] }\end{array}$ & p-value \\
\hline Proportion of stunted children & 2292 & $381[16.6]$ & & 2293 & $722[31.5]$ & \\
\hline Age of child & & & $<0.001$ & & & $<0.001$ \\
\hline 6-11 months & $329[14.4]$ & $71[21.6]$ & & $429[18.7]$ & $86[20.1]$ & \\
\hline $12-23$ months & $645[28.1]$ & $124[19.2]$ & & $650[28.4]$ & $220[33.9]$ & \\
\hline 24-35 months & $575[25.1]$ & $115[20.0]$ & & $540[23.6]$ & $185[34.3]$ & \\
\hline 36-47 months & $466[20.3]$ & $49[10.5]$ & & $424[18.5]$ & $160[37.7]$ & \\
\hline 48-59 months & $277[12.1]$ & $22[7.9]$ & & $250[10.9]$ & $71[28.4]$ & \\
\hline Sex of child & & & 0.510 & & & 0.002 \\
\hline Females & $1088[47.5]$ & $175[16.1]$ & & $1116[48.7]$ & $317[28.4]$ & \\
\hline Males & $1204[52.5]$ & $206[17.1]$ & & $1177[51.3]$ & $405[34.4]$ & \\
\hline \multicolumn{7}{|l|}{ Child Illness } \\
\hline Cough with short rapid breathing & & & 0.509 & & & 0.276 \\
\hline Yes & $213[52.5]$ & $36[16.9]$ & & $157[68.0]$ & $44[28.0]$ & \\
\hline No & $193[47.5]$ & $28[14.5]$ & & $73[31.6]$ & $20[27.4]$ & \\
\hline Diarrhea & & & 0.804 & & & 0.002 \\
\hline Yes & $414[18.1]$ & $67[16.2]$ & & $174[7.6]$ & $37[21.3]$ & \\
\hline No & 1876[81.9] & $313[16.7]$ & & $2117[92.4]$ & $685[32.4]$ & \\
\hline Maternal age (mean $[S D])^{*}$ & $28.9[6.0]$ & $28.1[5.9]$ & 0.005 & $28.4[5.8]$ & $28.5[5.7]$ & 0.788 \\
\hline Maternal education & & & 0.482 & & & 0.454 \\
\hline No education & $482[21.0]$ & $83[17.2]$ & & $404[17.6]$ & $126[31.2]$ & \\
\hline Primary & $293[12.8]$ & $56[19.1]$ & & $219[9.6]$ & $60[27.4]$ & \\
\hline Secondary & $1272[55.5]$ & $199[15.6]$ & & $1364[59.5]$ & $432[31.7]$ & \\
\hline Higher & $245[10.7]$ & $43[17.6]$ & & $306[13.3]$ & $104[34.0]$ & \\
\hline Maternal BMI** & & & $<0.001$ & & & 0.080 \\
\hline Thin and Normal $\left(<25 \mathrm{~kg} / \mathrm{m}^{2}\right)$ & $465[20.3]$ & $98[21.1]$ & & $460[20.1]$ & $129[28.0]$ & \\
\hline Overweight ( 25 to $30 \mathrm{~km} / \mathrm{g}^{2}$ ) & $897[39.1]$ & $181[20.2]$ & & $1043[45.5]$ & $351[33.7]$ & \\
\hline Obese $\left(>30 \mathrm{~kg} / \mathrm{m}^{2}\right)$ & $930[40.6]$ & $102[11.0]$ & & $790[34.5]$ & $242[30.6]$ & \\
\hline Perceived size of child at birth & & & 0.022 & & & 0.686 \\
\hline Very small or Small & $270[11.8]$ & $58[21.5]$ & & $214[9.3]$ & $70[32.7]$ & \\
\hline Average or Larger & $2017[88.2]$ & $322[16.0]$ & & $2079[90.7]$ & $652[31.4]$ & \\
\hline Birth Intervals & & & 0.087 & & & 0.035 \\
\hline$<24$ months & $261[15.6]$ & $45[17.2]$ & & $223[13.7]$ & 89[39.9] & \\
\hline 24-35 months & $459[27.5]$ & $81[17.7]$ & & $403[24.8]$ & $115[28.5]$ & \\
\hline 36-47 months & $379[22.7]$ & $65[17.2]$ & & $409[25.2]$ & $133[32.5]$ & \\
\hline $48+$ months & $572[34.2]$ & $72[12.6]$ & & $590[36.3]$ & $187[31.7]$ & \\
\hline \multicolumn{7}{|l|}{ Socioeconomic/avian flu variables } \\
\hline Household ownership of poultry/birds & & & 0.868 & & & 0.001 \\
\hline Yes & $700[30.5]$ & $115[16.43]$ & & $325[14.2]$ & $76[23.4]$ & \\
\hline No & $1592[69.5]$ & $266[16.7]$ & & $1967[85.8]$ & $645[32.8]$ & \\
\hline Residence & & & 0.153 & & & 0.280 \\
\hline Urban & $554[24.2]$ & $103[18.6]$ & & $558[24.3]$ & $186[33.3]$ & \\
\hline
\end{tabular}


Table 2 Proportion of stunting, 6-59 months, Lower Egypt 2005 ( $N=2292)$ and $2008(N=2293)$ (Continued)

\begin{tabular}{lllll}
\hline Rural & $1738[75.8]$ & $278[16.0]$ & $1735[75.7]$ & $536[30.9]$ \\
Wealth Quintile & & 0.044 & 0.157 & \\
Poorest & $277[12.1]$ & $43[15.5]$ & $229[9.6]$ & $60[27.3]$ \\
Poorer & $485[21.2]$ & $90[18.6]$ & $481[21.0]$ & $147[30.6]$ \\
Middle & $583[25.4]$ & $95[16.3]$ & $619[27.0]$ & $183[29.6]$ \\
Richer & $610[26.6]$ & $83[13.6]$ & $594[25.9]$ & $198[33.3]$ \\
Richest & $337[14.7]$ & $70[20.8]$ & $379[16.5]$ & $134[35.4]$ \\
\hline
\end{tabular}

Legend: N/A: Not applicable, data on avian influenza was not collected in 2005, as the outbreak occurred in 2006. ${ }^{*}$ Reference group is average age of mothers of non-stunted children. ${ }^{* *}$ No women were categorized as thin in 2005, and only 2 respondents in 2008 were thin.

evenly distributed across thin and normal, overweight and obese mothers.

The majority of mothers reported their child experiencing a cough with short rapid breaths. In Lower Egypt, in 2005 about half of mothers reported their child had a cough in the last two weeks. In Lower Egypt in 2008 and Upper Egypt in 2005 and 2008 two-thirds to three-quarters of mothers reported cough. However, cough was not associated with stunting in either survey year in Lower or Upper Egypt. Diarrhea was not associated with stunting, with the exception of 2008 in Lower Egypt. However, diarrhea was reported much less frequently in 2005 than 2008 (16\% and 21\% respectively), despite data collection during similar timeframes for both survey years.

In 2005, approximately $31 \%$ of households in Lower Egypt owned birds or poultry, while household ownership of birds or poultry significantly decreased to $14 \%$ in 2008 (55\% decrease). In Upper Egypt, ownership decreased from $50 \%$ in 2005 to $29 \%$ in 2008 (42\% decrease). In Lower Egypt, household ownership of birds or poultry was not significantly associated with stunting in 2005, but was significantly associated with stunting in 2008, with children in households owning birds or poultry significantly less likely to be stunted in bivariate analyses [OR $0.620 ; 95 \%$ CI $(0.47-0.82)$. In contrast, in Upper Egypt, in households with poultry, children were more likely to be stunted, regardless of survey year. Households without a modern flushing toilet were significantly more likely to be stunted (30.4\%) in Upper Egypt than those without a toilet (19\%) in Upper Egypt for both survey years, but not in Lower Egypt (data not shown). Children perceived to be very small or small at birth compared to average or larger had a significantly higher percentage of stunting in both survey years for Upper Egypt $(\mathrm{P}<0.01)$ but only in 2005 for Lower Egypt $(\mathrm{P}=0.022)$. Mothers with birth intervals less than 24 months since a previous birth were significantly associated with increased stunting in Lower Egypt for 2008 $(\mathrm{P}=.035)$ and $2005(\mathrm{P}=0.087$, compared to $48+$ months only) and for Upper Egypt in $2005(\mathrm{P}=0.046)$ (Table 2).
During both surveys, mothers were asked about foods and liquids consumed by themselves and their youngest child during the 24-hour period prior to the survey. Declining dietary diversity was noted in all breastfed children 6-23 months in Egypt, and notable in Lower Egypt (64.1\% versus $54.9 \%$, in 2005 and 2008, respectively; $\mathrm{P}<$ 0.001) and Upper Egypt 56.3\% versus 47.5\%, in 2005 and 2008 respectively; $\mathrm{P}<0.001$ (Figure 3 ). This mirrors a significant decrease in the percentage of breastfed children In Lower Egypt consuming five out of seven food groups between 2005 and 2008, including meat, poultry, and other organ meats (46.3\% versus $40.6 \%$; $\mathrm{P}<0.001)$, dairy products $(84.9 \%$ versus $78.4 \% ; \mathrm{P}<0.001)$, grains (85.1\% versus $81.9 \%$; $\mathrm{P}=0.05)$, vitamin-A rich foods and vegetables $(45.5 \%$ versus $31.1 \% ; \mathrm{P}<0.001)$, and other fruits and vegetables (55.2\% versus $37.0 \% ; \mathrm{P}<0 \quad .001)$ (Figure 4). Legumes and nuts and eggs consumption had non-significant decreases between survey years. Further, these analyses reveal a marked two-fold increase between the 2005 and 2008 EDHS in the percentage of Lower Egypt children 6 to 23 months of age who consumed sugary foods $(24.5 \%$ in 2005 versus $52.7 \%$ in 2008; $\mathrm{P}<0.001)$. For mothers in Lower Egypt, a significant decrease in consumption of three of seven food groups (i.e. dairy products, vitamin A rich foods and vegetables and other fruits and vegetables) $\mathrm{p}<0.001$ (Figure 4).

In contrast, in Upper Egypt, consumption of sugary foods in children 6 to 23 months significantly decreased from $44.7 \%$ to $39.7 \%$ ( $<<0.001$ ) (Figure 5). Significant decreases in the intake of five of seven food groups, including meat, poultry, and other organ meats $(56.5 \%$ versus 49.6\%; $\mathrm{P}=0.001)$, grains $(88.2 \%$ versus $83.5 \%$; $\mathrm{P}=0.001)$, legumes and nuts $(62.4$ to $51.0 \%, \mathrm{p}<0.001$, vitamin-A rich foods and vegetables (51.3\% versus $46.1 \% ; \mathrm{P}<0.001$ ), and other fruits and vegetables $(67.7 \%$ versus $37.0 \%$; $<0.001)$ was shown in Upper Egypt. Unlike Lower Egypt, Upper Egypt had a slight increase in consumption of dairy products by young children and a negligible change in eggs consumption. Mothers from Upper Egypt experienced significant declines in consumption of all food groups, with 
Table 3 Proportion of stunting, 6-59 months, Upper Egypt 2005 (N = 3893) and $2008(\mathrm{~N}=2708)$

\begin{tabular}{|c|c|c|c|c|c|c|}
\hline \multirow[t]{2}{*}{ Factor } & \multicolumn{3}{|l|}{2005} & \multicolumn{3}{|l|}{2008} \\
\hline & Total N [\%] & $\begin{array}{l}\text { Stunting, 6-59 } \\
\text { months } \mathrm{n}[\%]\end{array}$ & $\overline{p \text {-value }}$ & Total N [\%] & $\begin{array}{l}\text { Stunting, 6-59 } \\
\text { months n [\%] }\end{array}$ & $\overline{p \text {-value }}$ \\
\hline Proportion of stunted children & 3893 & $1120[28.8]$ & & 2708 & $590[21.8]$ & \\
\hline Age of child & & & $<0.001$ & & & $<0.001$ \\
\hline 6-11 months & $648[16.7]$ & $168[25.9]$ & & 495[18.3] & $66[13.3]$ & \\
\hline 12-23 months & $1131[29.1]$ & $374[33.1]$ & & $818[30.2]$ & $229[28.0]$ & \\
\hline 24-35 months & $958[24.6]$ & $276[28.8]$ & & $626[23.1]$ & $138[22.0]$ & \\
\hline 36-47 months & $702[18.0]$ & $199[28.4]$ & & $468[17.3]$ & $92[19.7]$ & \\
\hline 48-59 months & $454[11.7]$ & $103[22.7]$ & & $301[11.1]$ & $65[21.5]$ & \\
\hline Sex of child & & & 0.001 & & & 0.213 \\
\hline Females & 1853[47.6] & $485[26.2]$ & & 1296[47.9] & $269[20.7]$ & \\
\hline Males & $1040[52.4]$ & $635[31.1]$ & & $1412[52.1]$ & $321[22.7]$ & \\
\hline \multicolumn{7}{|l|}{ Child Illness } \\
\hline Cough with short rapid breathing & & & 0.342 & & & 0.990 \\
\hline Yes & $532[60.8]$ & $132[24.8]$ & & $424[73.9]$ & $85[20.1]$ & \\
\hline No & $343[39.2]$ & $95[27.7]$ & & $150[26.1]$ & $30[20.0]$ & \\
\hline Diarrhea & & & 0.210 & & & 0.967 \\
\hline Yes & $1009[25.9]$ & $275[27.3]$ & & $364[13.4]$ & $79[21.7]$ & \\
\hline No & $2881[74.1]$ & $845[29.3]$ & & $2344[86.6]$ & $511[21.8]$ & \\
\hline Maternal age (mean $[S D])^{*}$ & $29.0[6.5]$ & $28.8[6.4]$ & 0.199 & $29.2[6.5]$ & $29.3[6.5]$ & 0.724 \\
\hline Maternal education & & & 0.004 & & & $<0.001$ \\
\hline No education & $1704[43.8]$ & $526[30.9]$ & & $1068[39.4]$ & $274[25.7]$ & \\
\hline Primary & $526[13.5]$ & $155[29.5]$ & & $299[11.0]$ & $68[22.7]$ & \\
\hline Secondary & 1466[37.7] & $400[27.3]$ & & $1128[41.7]$ & $219[19.4]$ & \\
\hline Higher & 197[5.1] & $39[19.8]$ & & 213[7.9] & $29[13.6]$ & \\
\hline Maternal BMI** & & & 0.003 & & & 0.197 \\
\hline Thin and Normal $\left(<25 \mathrm{~kg} / \mathrm{m}^{2}\right)$ & 1533[39.4] & $487[31.8]$ & & $1117[41.3]$ & $258[23.1]$ & \\
\hline Overweight ( 25 to $30 \mathrm{~km} / \mathrm{g}^{2}$ ) & $1408[36.2]$ & $387[27.5]$ & & $991[36.6]$ & $216[21.8]$ & \\
\hline Obese $(>30$ kg/m²) & $952[24.5]$ & $246[25.8]$ & & $600[22.2]$ & $116[19.3]$ & \\
\hline Perceived size of child at birth & & & $<0.001$ & & & 0.005 \\
\hline Very small or Small & $619[16.0]$ & $229[37.0]$ & & $478[17.7]$ & $127[26.6]$ & \\
\hline Average or Larger & $3251[84.0]$ & $882[27.1]$ & & $2230[82.4]$ & $463[20.8]$ & \\
\hline Birth Intervals & & & 0.046 & & & 0.399 \\
\hline$<24$ months & $657[20.9]$ & $204[31.1]$ & & $373[17.5]$ & $87[23.3]$ & \\
\hline 24-35 months & $969[30.8]$ & $285[29.4]$ & & $636[29.8]$ & $143[22.5]$ & \\
\hline 36-47 months & $642[20.4]$ & $194[30.2]$ & & $455[21.3]$ & $113[24.8]$ & \\
\hline $48+$ months & $877[27.9]$ & $221[25.2]$ & & $670[31.4]$ & $138[20.6]$ & \\
\hline \multicolumn{7}{|l|}{ Socioeconomic/avian influenza factors } \\
\hline Household ownership of poultry/birds & & & 0.003 & & & 0.029 \\
\hline Yes & $1951[50.1]$ & $603[30.9]$ & & $783[28.9]$ & $192[24.5]$ & \\
\hline No & $1942[49.9]$ & $517[26.6]$ & & 1923[71.1] & $398[20.7]$ & \\
\hline Residence & & & 0.004 & & & 0.012 \\
\hline Urban & $988[25.4]$ & $249[25.2]$ & & $715[26.4]$ & $132[18.5]$ & \\
\hline
\end{tabular}


Table 3 Proportion of stunting, 6-59 months, Upper Egypt 2005 ( $N=3893)$ and $2008(N=2708)$ (Continued)

\begin{tabular}{lllll}
\hline Rural & $2905[74.6]$ & $871[30.0]$ & $1993[73.6]$ & {$[23.0]$} \\
Wealth Quintile & & $<0.001$ & $<0.001$ & \\
Poorest & $1372[35.2]$ & $469[34.2]$ & $1038[38.2]$ & $263[25.3]$ \\
Poorer & $1019[26.2]$ & $287[28.2]$ & $668[24.7]$ & $153[22.9]$ \\
Middle & $729[18.7]$ & $197[27.0]$ & $446[16.5]$ & $86[19.3]$ \\
Richer & $447[11.5]$ & $101[22.6]$ & $273[10.1]$ & $51[18.7]$ \\
Richest & $326[8.4]$ & $66[20.3]$ & $283[10.5]$ & $37[13.1]$ \\
\hline
\end{tabular}

Legend: N/A: Not applicable, data on avian influenza was not collected in 2005, as the outbreak occurred in $2006 .{ }^{*}$ Reference group is average age of mothers of non-stunted children. ${ }^{* *}$ No women were categorized as thin in 2005, and only 2 respondents in 2008 were thin.

the exception of vitamin A rich fruits and vegetables (Figure 5).

Determinants of stunting in Lower Egypt, 2005 and 2008

Table 4 displays multivariable regression adjusted analyses of factors associated with stunting in 2005 and 2008 for Lower Egypt. After controlling for place of residence, household wealth quintile and sex of child, household ownership of poultry or birds and child's age group were significantly associated with stunting, while short birth interval was marginally significant. Households that owned poultry or birds were $41.7 \%$ less likely to have a stunted child between 6 and 59 months in Lower Egypt [aOR 0.582; 95\% CI $(0.42,0.81) \mathrm{P}=0.002$ ]. Compared to 6-11 month old children (referent category), children 12-47 months of age were 2.12-2.34 times more likely to be stunted. This relationship was significant for $12-23$ months $(\mathrm{P}<0$.001), 24-35 months $(\mathrm{P}=0.001)$, and $36-47$ months $(\mathrm{P}<0.001)$, with the greatest risk being in the 36-47 months category (aOR 2.34; 95\% CI $(1.50,3.63)$. Women who had a birth interval less than 24 months before their latest pregnancy were $38 \%$ more likely to have a stunted child, compared to women with longer birth intervals between 36 and 47 months [aOR 1.383; 95\% CI $(.98,1.950)$ ]. Women with birth intervals between 24-35 months were less likely to have a stunted child [aOR .833; 95\% CI (0.60, 1.51)], whereas women with birth intervals 48 months or longer had a slightly higher odds of having a stunted child [aOR 1.01; 95\% CI $(0.76,1.34)]$, compared to women in the referent category of 24-35 months.

\section{Determinants of stunting in Upper Egypt, 2005 and 2008}

Table 5 displays multivariable regression adjusted analyses of factors associated with stunting in 2005 and 2008 for Upper Egypt. After controlling for place of residence, household wealth quintile and sex of child, child's age group, perceived small or average birth size, and birth interval of 48 months or longer since previous birth were significantly associated with stunting. In contrast to Lower Egypt, the site of the AI outbreak, household ownership of poultry or birds was not associated with stunting in Upper Egypt. Women with the longest birth intervals (48 months or longer) had 33.4\% reduced

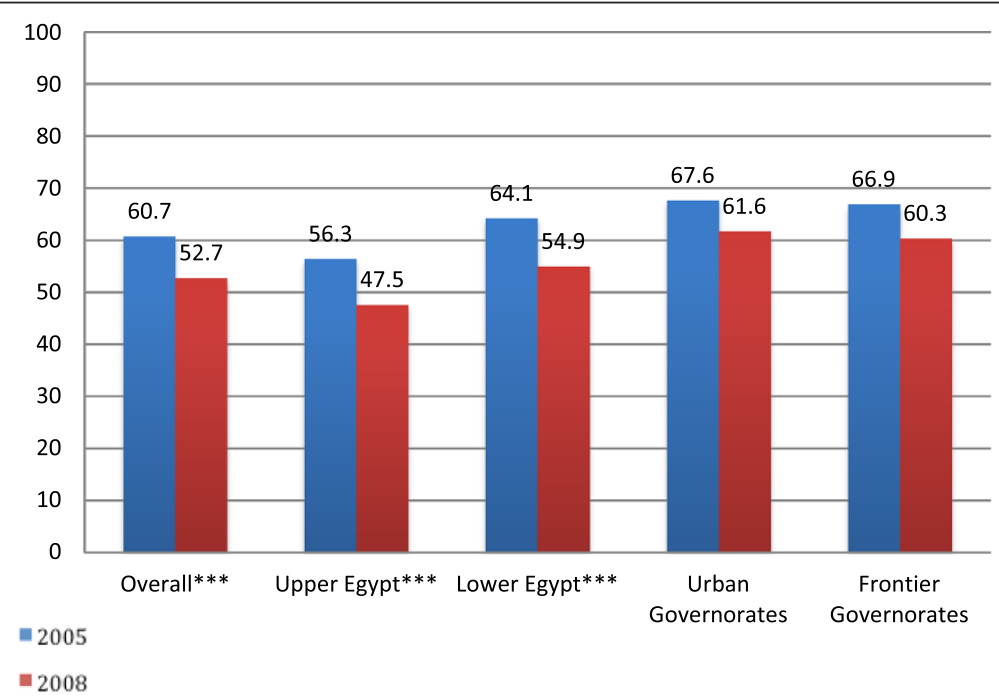

Figure 3 Proportion of children, 6-23 months, meeting minimum dietary diversity, Egypt 2005 and 2008. Legend: ${ }^{* * *} P<0.001$. 


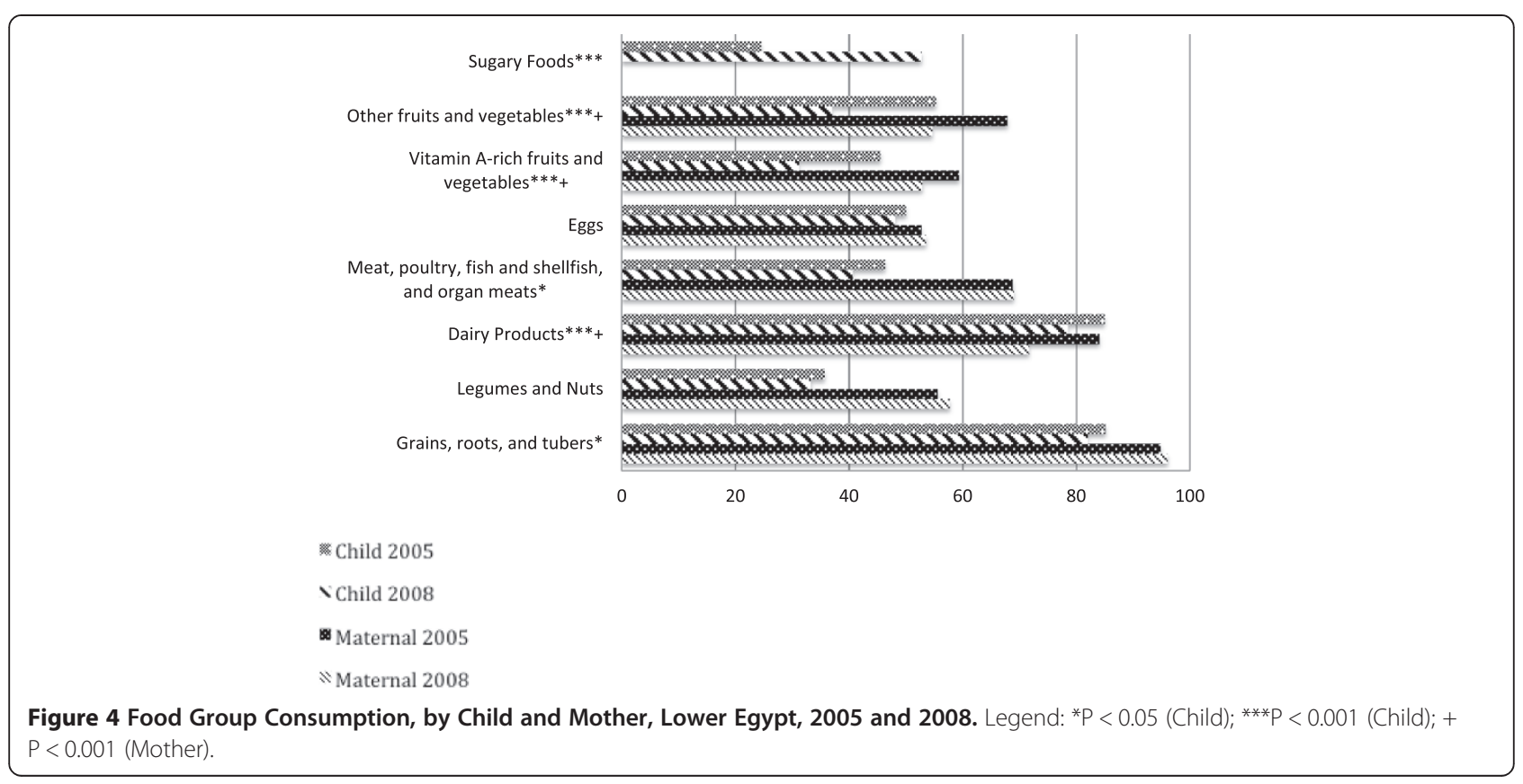

odds of having a stunted child [aOR 0.666 (95\% CI $0.495,0.897)]$.

Similar to Lower Egypt, older children in Upper Egypt were more likely to be stunted in comparison to the referent group (6-11 months) in 2008 but not 2005. Stunting peaked at $12-23$ months $(\mathrm{P}<0.001)$ and the remaining risks for stunting at 24-35 months $(\mathrm{P}=0.022), 36-47$ months $(\mathrm{P}=.043)$ though high, were attenuated compared to Lower Egypt, with 22-32\% less risk of stunting in these age groups, comparatively.

\section{Discussion}

This analysis focused on determinants of stunting in children aged 6 to 59 months in Lower Egypt in comparison to Upper Egypt, within the context of the 2006 AI outbreak and rising food insecurity in between the

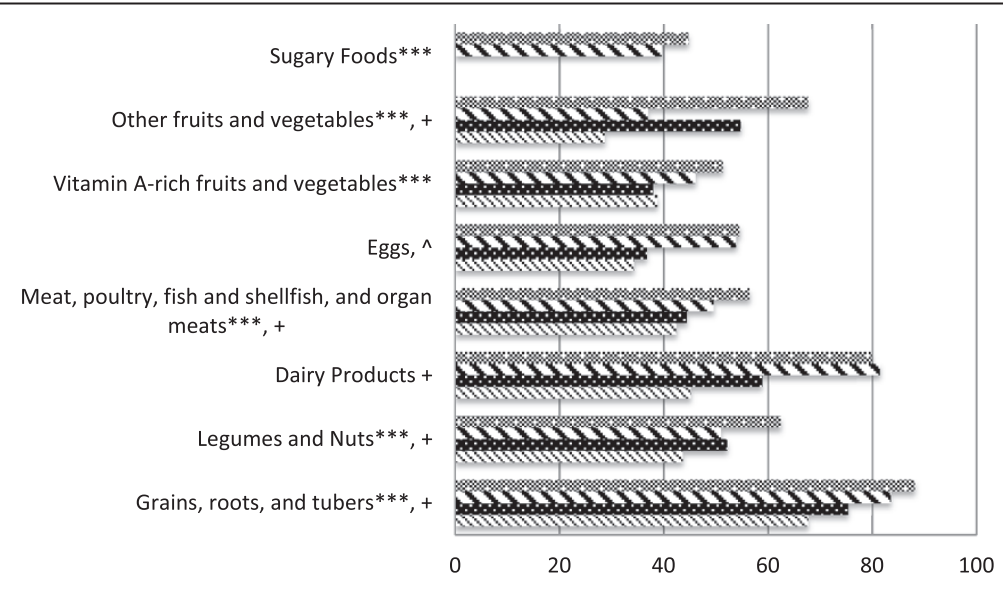

Child 2005

Child 2008

Maternal 2005

« Maternal 2008

Figure 5 Food Group Consumption, by Child and Mother, Upper Egypt, 2005 and 2008. ${ }^{*} P<0.05$ (Child); ${ }^{* * *} P<0.001$ (Child); $\wedge P<0.05$ (Mother\}; $+\mathrm{P}<0.001$ (Mother). 
Table 4 Determinants of stunting in children 6-59 months - adjusted odds ratio, Lower Egypt 2005 (N= 2292) and 2008 ( $N=2293)$

\begin{tabular}{|c|c|c|c|c|c|c|}
\hline Factor & Adjusted OR 2005 & P-value & $95 \% \mathrm{Cl}$ & Adjusted OR 2008 & P-value & $95 \% \mathrm{Cl}$ \\
\hline \multicolumn{7}{|l|}{ Residence } \\
\hline \multicolumn{7}{|l|}{ Urban (ref) } \\
\hline Rural & 0.974 & 0.893 & $0.667,1.423$ & 0.984 & 0.935 & $0.676,1.434$ \\
\hline \multicolumn{7}{|l|}{ Age of child } \\
\hline \multicolumn{7}{|l|}{ 6-11 months (ref) } \\
\hline 12-23 months & 0.841 & 0.459 & $0.531,1.332$ & 2.261 & $<0.001$ & $1.516,3.372$ \\
\hline 24-35 months & 1.015 & 0.953 & $0.615,1.677$ & 2.120 & 0.001 & $1.390,3.233$ \\
\hline 36-47 months & 0.458 & 0.005 & $0.265,0.790$ & 2.335 & $<0.001$ & $1.502,3.632$ \\
\hline 48-59 months & 0.382 & 0.004 & $0.199,0.732$ & 1.487 & 0.098 & $0.929,2.380$ \\
\hline \multicolumn{7}{|l|}{ Sex of child } \\
\hline \multicolumn{7}{|l|}{ Females (ref) } \\
\hline Males & 1.031 & 0.829 & $0.782,1.358$ & 1.289 & 0.023 & $1.036,1.603$ \\
\hline \multicolumn{7}{|l|}{ Wealth Quintile } \\
\hline Poorest (ref) & ref & ref & ref & ref & ref & ref \\
\hline Poorer & 0.932 & 0.793 & $0.548,1.585$ & 1.099 & 0.645 & $0.735,1.641$ \\
\hline Middle & 0.874 & 0.621 & $0.511,1.495$ & 1.023 & 0.908 & $0.692,1.512$ \\
\hline Richer & 0.593 & 0.084 & $0.327,1.073$ & 0.982 & 0.935 & $.0633,1.523$ \\
\hline Richest & 1.083 & 0.806 & $0.572,2.050$ & 1.158 & 0.585 & $0.684,1.958$ \\
\hline \multicolumn{7}{|l|}{ Perceived size of child at birth } \\
\hline Very small or Small & 1.201 & 0.404 & $0.781,1.847$ & 1.201 & 0.342 & $0.823,1.752$ \\
\hline \multicolumn{7}{|l|}{ Average or Larger (ref) } \\
\hline \multicolumn{7}{|l|}{ Birth Intervals } \\
\hline$<24$ months & 1.155 & 0.523 & $0.741,1.802$ & 1.383 & 0.065 & $0.981,1.951$ \\
\hline 24-35 months & 1.129 & 0.573 & $0.740,1.721$ & 0.833 & 0.269 & $0.603,1.152$ \\
\hline \multicolumn{7}{|l|}{ 36-47 months (ref) } \\
\hline $48+$ months & 0.716 & 0.111 & $0.475,1.080$ & 1.008 & 0.956 & $0.760,1.337$ \\
\hline \multicolumn{7}{|l|}{ Avian influenza } \\
\hline Household ownership of poultry/birds & 1.045 & 0.805 & $0.735,1.486$ & 0.583 & 0.002 & $0.418,0.814$ \\
\hline
\end{tabular}

Significant predictors bold-faced, p-values.

2005 and 2008 EDHS surveys. Previous multivariable analyses of EDHS data showed similar results in Lower Egypt, increased stunting with age, among boys, and with longer birth intervals in children younger than five years of age [25]. In Kenya, modeled estimates of the potential impact of AI found that reduced consumption of chicken would increase stunting [21].

The pattern of stunting differed between the two areas of Egypt. These analyses suggest that events which contributed to a rise in stunting in Lower Egypt, were likely different from events in Upper Egypt, which protected children from stunting within the same time period between 2005 and 2008.

Household ownership of poultry was a significant predictor of stunting, with children 6 to 59 months of age less likely to be stunted in Lower Egypt, which was confirmed in prior analyses of EDHS data that reported a $32 \%$ reduced odds of stunting in households with poultry [25]. The effect of the AI is revealed in these analyses. Children 24-47 months of age in Lower Egypt, who were alive and likely affected at the time of the AI outbreak in 2006, had comparatively higher risk of stunting than their younger counterparts in 2008 and 2005 in either Lower or Upper Egypt.

Following the report of the first human case of highly pathogenic AI (H5N1) virus in March 2006[29], the Egyptian government conducted mass removal of chickens and eggs and vaccinations of poultry through 2009 in response to the AI outbreak in Lower Egypt [30]. The AI resulted in decreased supplies and household consumption of poultry and eggs [6,23]. Raising poultry through "backyard flocks" is an important component of 
Table 5 Determinants of stunting in children 6-59 months - adjusted odds ratio, Upper Egypt 2005 (N = 3893$)$ and 2008 ( $N=2708)$

\begin{tabular}{|c|c|c|c|c|c|c|}
\hline Factor & Adjusted OR 2005 & P-value & $95 \% \mathrm{Cl}$ & Adjusted OR 2008 & P-value & $95 \% \mathrm{Cl}$ \\
\hline \multicolumn{7}{|l|}{ Residence } \\
\hline \multicolumn{7}{|l|}{ Urban (ref) } \\
\hline Rural & 1.198 & 0.319 & 0.8401 .710 & 0.933 & 0.678 & $0.672,1.295$ \\
\hline \multicolumn{7}{|l|}{ Age of child } \\
\hline \multicolumn{7}{|l|}{ 6-11 months (ref) } \\
\hline 12-23 months & 1.494 & 0.006 & $1.122,1.991$ & 2.616 & $<0.001$ & $1.728,3.960$ \\
\hline 24-35 months & 1.047 & .773 & $.764,1.436$ & 1.648 & 0.022 & $1.074,2.527$ \\
\hline 36-47 months & 0.976 & .883 & $.701,1.357$ & 1.570 & 0.043 & 1.014. 2.430 \\
\hline 48-59 months & 1.053 & .795 & $.714,1.551$ & 1.833 & 0.018 & $1.109,3.030$ \\
\hline \multicolumn{7}{|l|}{ Sex of child } \\
\hline \multicolumn{7}{|l|}{ Females (ref) } \\
\hline Males & 1.223 & .044 & $1.005,1.487$ & 1.077 & 0.536 & $0.851,1.365$ \\
\hline \multicolumn{7}{|l|}{ Wealth Quintile } \\
\hline \multicolumn{7}{|l|}{ Poorest (ref) } \\
\hline Poorer & 0.599 & $<.001$ & $0.462,0.778$ & 0.879 & 0.335 & $0.677,1.142$ \\
\hline Middle & 0.603 & 0.001 & $0.448,0.813$ & 0.656 & 0.014 & $0.469, .919$ \\
\hline Richer & 0.481 & 0.001 & $0.315,0.733$ & 0.686 & 0.095 & $0.441,1.068$ \\
\hline Richest & 0.463 & 0.008 & $0.263,0.815$ & 0.519 & 0.013 & $0.310,0.868$ \\
\hline \multicolumn{7}{|l|}{ Perceived size of child at birth } \\
\hline Very small or Small & 1.444 & 0.006 & $1.112,1.875$ & 1.475 & 0.007 & $1.114,1.954$ \\
\hline \multicolumn{7}{|l|}{ Average or Larger (ref) } \\
\hline \multicolumn{7}{|l|}{ Birth Intervals } \\
\hline$<24$ months & 0.983 & 0.904 & $0.746,1.296$ & 0.804 & 0.210 & $0.571,1.132$ \\
\hline 24-35 months & 1.066 & 0.648 & $0.810,1.402$ & 0.774 & 0.112 & $0.565,1.061$ \\
\hline \multicolumn{7}{|l|}{ 36-47 months (ref) } \\
\hline $48+$ months & 0.814 & 0.191 & $0.598,1.108$ & 0.666 & 0.008 & $0.495,0.897$ \\
\hline \multicolumn{7}{|l|}{ Avian influenza } \\
\hline Household ownership of poultry/birds & 0.943 & 0.572 & $0.769,1.157$ & 1.185 & 0.182 & $0.923,1.522$ \\
\hline
\end{tabular}

Significant predictors bold-faced, p-values.

Egyptian culture, a source of animal protein [31]. Many women, as primary caretakers of poultry, reduced their financial independence and their ability to take care of household needs, which was a source of tension and intra-household conflicts, and may have impaired their ability to care for the growth of young children in Lower Egypt [32].

Between 2005 and 2008, when the rapid increase in stunting occurred, a decline in the variety of foods consumed by Egyptian children and substitution of nutritious foods with less nutritive foods was noted in Lower Egypt. Poor infant and young child feeding is a cause of stunting [3,7], and Egyptian children are fed small amounts of food, of little quality, and limited variety [33]. Dietary diversity decreased across all regions of Egypt between 2005 and 2008 EDHS, with large and significant decreases found in Lower Egypt and Upper Egypt".

Dietary diversity has been associated with height/ length for age in a nine country analyses, which point to diversity as a measure of quality of the diet [34]. In Lower Egypt, we found a significant decline between 2005 and 2008, in child consumption of the following food groups: vitamin A rich fruits and vegetables, other fruits and vegetables, meat, poultry, fish and other animal source foods, grains, roots and tubers and dairy products. During this same time period, a greater than twofold increase in child level intake of sugary foods suggests substitution of high nutritive animal-source foods with less nutritive foods, such as snack cakes and biscuits, commonly consumed by toddlers and perceived as "light", simple and "easy to digest" [33]. Sugary foods 
provide little nutritional value to the diet and can decrease a child's appetite for more nutritious foods [35]. In contrast, in Upper Egypt, a decrease in sugary foods was found between 2005 and 2008. Other regions of Egypt noted small increases in consumption of sugary foods.

This decline in reduced dietary diversity is supported by families' personal experiences of economic loss and changes in dietary habits, in response to fear of illness during the AI outbreak, especially for children [33]. Adults were often consuming "store-bought" frozen meat or previously frozen chicken, although with less frequency than prior to the AI outbreak. Yet, children were fed different, less nutritive foods than elders and were not fed chicken or meat. As relayed by one father from Lower Egypt, "The family started replacing birds with meat and fish ....our budget was affected and instead of having [animal] protein every day we started having it only once or twice a week. During avian influenza we were eating [frozen] birds they were buying and the children's diet was affected like the whole family. Every day each family member used to have a piece of chicken accompanying the food, this was replaced by fish and meat and we cannot bear the price of these foods to be included in the diet so we served [meat] only once or twice a week and sometimes...replaced chicken with eggs" [33].

Families relayed that meat and fish are very expensive - evidence of growing food insecurity in the face of economic crises. One father lamented "we started replacing these foods with rice, cooked vegetables and beans for a year and a half...the food for children was totally different from the elders. The children's diet included yogurt, milk, and [sugary] biscuits... elder members had rice and vegetables." Replacement of animalsource foods, with beans, lentils, and chickpeas, and an overreliance on cereals and tubers have been documented previously [32,33,36,37]. Families expressed fears of animal source foods (i.e. chicken, eggs) as a source of indigestion and illness for young children, and often withheld these foods, as a response to fear of AI in Lower Egypt [33]. These observations were documented during implementation research under the Maternal and Child Health Integrated Program (MCHIP), the United States Agency for International Development (USAID) project for maternal and child health which worked with local community organizations to improve health service delivery and nutritional status.

Animal source foods can prevent malnutrition and are key to the healthy growth of young children. Children, 18-30 months of age, not fed adequate amounts of animal-source foods, had poor dietary intake of key vitamins and minerals and higher prevalence of stunting in a multi-country study in Egypt, Mexico and Kenya [38,39]. Animal source foods provide key nutrients, such as iron, zinc and vitamin B12 - which are not found in plant-based diets or foods rich in grains [39-42]. These foods are critical for stimulating physical growth, better cognitive functioning and development during childhood [41].

Significantly decreased dietary diversity and reduced poultry meat consumption among children paralleled a reduction in number of birds raised in homes following the AI outbreak. By 2008, Lower Egypt saw greater than two times reduction in household ownership of poultry among stunted children, 6-59 months of age (except for 24-35 months of age, which saw an $11 \%$ decrease) compared to 2005. Although reductions in poultry ownership and likely consumption were found among stunted children in Upper Egypt, the decrease was not as marked for older children (24-48 months of age - approximately $33 \%)$. This significant reduction in poultry consumption was unique to Lower Egypt and not experienced to the same degree in Upper Egypt.

In Lower Egypt, semi-urban families had higher incomes than rural families in Upper Egypt (with 11\% categorized as poor in Lower Egypt), and were likely able to afford less nutritious snack foods, which served as a substitute for poultry and eggs - as these foods allayed perceived fears of illness [22,33]. This mirrored the tendency for greater levels of stunting in middle to richest wealth quintiles in Lower Egypt. On the other hand, in Upper Egypt, the middle to richest wealth quintiles were protective for stunting in Upper Egypt. With half of the population deemed poor, families from Upper Egypt had less disposable income to afford sugary foods. In addition, in Upper Egypt, the multi-year investment of international development projects, such as Healthy Mother/ Healthy Child, a USAID-funded Project implemented by John Snow International, showed significant reductions in maternal mortality rates in Upper Egypt and employed community education and mobilization for maternal reproductive health, mass media education for maternal and child health, including birth preparedness, newborn care, community outreach and behavior change from 1998-2004 [43]. The presence and inputs of this project, may have contributed to staving off changes in stunting between the survey years, and the varied associations between Lower Egypt and Upper Egypt, as communities had higher awareness of better health and received counseling on breastfeeding practices, which may have led to better feeding practices.

In Lower Egypt, less development inputs focused on health and nutrition, which could have prevented sugary food consumption and provided monitoring, guidance and support of optimal infant and young child feeding practices at the community level. In addition, gender differences in growth, reveal male children from Lower Egypt, were nearly $30 \%$ more likely to be stunted in 
2008 than females, whereas in Upper Egypt, males were $8 \%$ more likely to be stunted (aOR 1.077, 95\% CI:0.8511.365 , $\mathrm{p}$ value $=0.536$ ). Male children have increased nutrient needs in comparison to females, and are often more physically active than girls, therefore some deficit or differences in growth can be expected, particularly with no to little programming to encourage optimal feeding for young boys and girls $[44,45]$. Yet, these results point to and confirm the worsening food insecurity situation in Lower Egypt than Upper Egypt.

Our data also reveal varying patterns in maternal intake in comparison to child consumption of foods, by region. Our analyses revealed a significant reduction in child intake across five food groups, whereas comparatively, mothers reported a reduction in only three of seven food groups in Lower Egypt. There was no change in the proportion of Lower Egypt mothers consuming meat, poultry, or fish between the two survey years, whereas children had significantly decreased consumption of this particular food group, following the AI outbreak. Yet, mothers in Lower Egypt did not adopt the same food restrictions for themselves, and likely may have added processed foods and sugary foods to their diet, given recent trends and government subsidies of sugar, oil and other low-nutrient dense foods [46-49]. These data suggest that maternal dietary intake does not necessarily correlate with child level intake when mothers may be fearful of feeding their children certain foods possibly due to fear of illness/ disease. Mothers and elder family members also reported the consumption of frozen, store-bought chicken and meat, following the mass removal of chickens in Lower Egypt [33]. Withholding or restricting foods for children but not mothers or other adults $[50,51]$ may be due to a number of factors, including, parenting styles, education or income, maternal weight and cultural beliefs and knowledge, or the influence of family members, which can affect how frequent, how much, and what kinds of food are fed to children $[33,46,50,52]$.

Longer birth intervals predicted less likelihood of stunting, which has also been found in a fifty-two country analyses of DHS data [53]. Children conceived after an interval of only 12 to 17 months were 25 percent more likely to be stunted, than children conceived after 36-47 months. A systematic literature review of the effects of birth spacing on maternal and child nutritional status also revealed longer birth interval more than 36 months is associated with a ten to fifty percent reduction in stunting [54]. The associations are in the expected direction and consistent with other studies suggesting increased risk of negative child health outcomes with short birth intervals ( $<24$ months) or long birth intervals (48 months or longer), but that risk decreases in the recommended birth interval of 24-35 months $[53,55]$. Closely spaced pregnancies also can deplete mothers' nutrient stores and result in maternal depletion syndrome, as well as reduce the ability of a mother to care for her children $[42,53,56,57]$.

\section{Strengths and limitations}

There are several strengths of these analyses. It is based on data from nationally representative demographic and health surveys that used internationally validated questionnaires, with high response rates (>98\%) and oversampling in remote areas [6]. The current study provides a comparison of the 2005 and 2008 EDHS surveys and examines the changes in the determinants of stunting in Egypt, with a focus on Lower Egypt and the influence of the AI outbreak, maternal nutrition and infant and young child feeding practices, which has not been examined previously.

These analyses have several limitations. Survey data is cross-sectional in nature and therefore attribution and causal inferences cannot be made. Participants must also rely on memory to recall information collected by questionnaires, which may contribute to possible memory bias. Food consumption was ascertained only in the past 24 hours, and did not assess the quantity of food or frequency which foods were consumed by food group, in mothers and children, this may have blunted the ability to detect an association with stunting in our models, a challenge found in other investigations using survey data [34,41]. Stunting is a process that occurs over the first few years of life, and the cross-sectional nature of the data may have hindered the ability to see an association between dietary intake and stunting in multivariable models. The quality of anthropometric data collected in the past surveys and possible inaccuracies in the reporting of children's ages may also have limited the ability to detect associations with stunting [6]. Further, data on infant and young child feeding practices with respect to AI is limited and only available for children 623 months of age.

\section{Conclusions}

Stunting significantly increased in Lower Egypt compared to Upper Egypt among 6-59 month old children between the 2005 and 2008 EDHS. The removal of poultry due to the AI outbreak expanded food insecurity to a greater number of households in the face of deteriorating economic conditions in Egypt. Reduced dietary diversity was evidenced by decreased consumption of food groups, declining variety of foods fed to young children, and the lack of poultry raised and owned by households, which were associated with stunting. At the same time, there was a significant increase between 2005 and 2008 in the consumption of sugary foods being consumed by children in Lower Egypt but not in Upper 
Egypt. This increase may have been due to a substitution of more nutritious foods with sugary foods because fear of illness due to AI and/or a significant increase in the penetration of these foods to Lower Egypt and not in Upper Egypt. Children that were alive and likely affected by the outbreak of 2006 had the highest levels of stunting in 2008, which may have reflected the contributions of decline in a diverse diet fed to children and increased availability of sugary foods in Lower Egypt during this period of time. Mothers were less likely to decrease the diversity of their diet.

Short birth intervals was associated with greater likelihood of a child being stunted. For the future, the increasing availability and use of sugary foods needs to be stemmed in the country. Intake of sugary foods and junk foods should be monitored in other countries as well, given the growing frequency in use and demand for these foods [58,59]. Mothers need advice on infant and young child feeding to improve children's dietary intake and reduce intake of sugary foods. Mothers in Egypt and elsewhere should be counselled, to feed the nutritious foods they are consuming to children and on birth spacing for two years for optimal growth and development and to prevent stunting.

\section{Additional file}

Additional file 1: The association between child stunting and water and sanitation variables in bivariate and multivariable analyses, Lower and Upper Egypt, 2005 and 2008 EDHS. Bivariate and multivariable analyses of child stunting and water and sanitation variables using 2005 and 2008 EDHS data. Regression models presented in main manuscript, are presented in this file, including water and sanitation variables.

\section{Abbreviations}

EDHS: Egypt Demographic and Health Survey; Al: Avian influenza; aOR: Adjusted odds ratio; Cl: Confidence interval; SD: Standard deviation.

\section{Competing interests}

The authors declare that they have no competing interests.

\section{Authors' contributions}

JK directed data analyses, with input from RG. FE conducted the initial analyses and statistical modeling. ML conducted further analyses and preparation of tables and figures for the manuscript. JK and ML prepared the manuscript, with inputs from FE and RG, who reviewed manuscript drafts. All authors reviewed, read and approved the final manuscript.

\section{Acknowledgements}

We are grateful for the funding provided by the United States Agency for International Development (USAID) under the USAID-funded Maternal and Child Integrated Program (MCHIP) Project under the cooperative agreement GHS-A-00-08-00002-000. We would like to thank the Measure Demographic and Health Survey for providing Demographic and Health Survey data used in this analysis. We also thank Monica Kothari with PATH and ICF Macro who reviewed and provided technical comments to this paper.

\section{Author details}

${ }^{1}$ Maternal and Child Health Integrated Program (MCHIP), 1776 Massachusetts Ave NW, Suite 300, Washington DC, USA. ${ }^{2}$ PATH, Maternal, Child Health and Nutrition (MCHN), 455 Massachusetts Ave NW, Suite 1000, Washington DC 20001, USA. ${ }^{3}$ El-Zanaty and Associates, Cairo, Egypt. ${ }^{4}$ Department of
Prevention and Community Health, George Washington University Milken Institute School of Public Health, Washington DC, USA.

Received: 21 November 2014 Accepted: 9 March 2015

Published online: 25 March 2015

\section{References}

1. de Onis M, Garza C, Onyango AW, Martorell R. WHO child growth standards. Acta Paediatr. 2006;450 (Suppl.):1-101.

2. Victora CG, de Onis M, Hallal PC, Blossner M, Shrimpton R. Worldwide timing of growth faltering: revisiting implications for interventions. Pediatrics. 2010;125(3):e473-80.

3. Stewart CP, lannotti L, Dewey KG, Michaelsen KF, Onyango AW. Contextualising complementary feeding in a broader framework for stunting prevention. Matern Child Nutr. 2013;9 Suppl 2:27-45.

4. World-Bank. Repositioning nutrition as central to development: a strategy for large-scale action. Washington, DC: World Bank; 2006.

5. Food and Agriculture Organization. The double burden of malnutrition: Case studies from six developing countries. In: Food \& Nutrition Paper. Rome, Italy: Food and Agriculture Organization; 2006.

6. El-Zanaty F, Way A. Egypt demographic and health survey 2008. Cairo, Egypt: Ministry of Health and Population, National Population Council, ElZanaty and Associates, and ORC Macro; 2009.

7. Black RE, Victora CG, Walker SP, Bhutta ZA, Christian P, de Onis M, et al Maternal and child undernutrition and overweight in low-income and middle-income countries. Lancet. 2013;382(9890):427-51.

8. World Food Programme. Cost of hunger in Egypt: implications of child undernutrition on the social and economic development in Egypt. In: The social and economic impact of child undernutrition in Egypt. Cairo, Egypt: Egyptian Cabinet Information Decision Support Center; 2013.

9. Abegunde DO, Mathers CD, Adam T, Ortegon M, Strong K. The burden and costs of chronic diseases in low-income and middle-income countries. Lancet. 2007;370(9603):1929-38.

10. Update on highly pathogenic avian influenza in animals. [http://www.oie. int/animal-health-in-the-world/update-on-avian-influenza/2014/]

11. Krebs NF, Mazariegos M, Tshefu A, Bose C, Sami N, Chomba E, et al. Meat consumption is associated with less stunting among toddlers in four diverse low-income settings. Food Nutr Bull. 2011;32(3):185-91.

12. Leroy JL, Frongillo EA. Can interventions to promote animal production ameliorate undernutrition? J Nutr. 2007;137(10):2311-6.

13. Alders R, Awuni JA, Bagnol B, Farrell P, de Haan N. Impact of avian influenza on village poultry production globally. Ecohealth. 2014;11(1):63-72.

14. World Food Programme. Status of poverty and food security in Egypt: analysis and policy recommendations, Preliminary summary report. Egypt: World Food Programme; 2013.

15. Ismail NA, Ahmed HA. Knowledge, attitudes and practices related to avian influenza among a rural community in Egypt. J Egypt Public Health Assoc. 2010;85(1-2):73-96.

16. Hawkes C, Ruel M. From agriculture to nutrition: pathways, synergies, and outcomes. 40th ed. Washington DC: The World Bank and Agriculture and Rural Development (ARD); 2008.

17. Victora CG, Adair L, Fall C, Hallal PC, Martorell R, Richter $L$, et al. Maternal and child undernutrition: consequences for adult health and human capital. Lancet. 2008;371(9609):340-57.

18. Bwibo NO, Neumann CG. The need for animal source foods by Kenyan children. J Nutrit. 2003;133(11 Suppl 2):3936S-40S.

19. Murphy SP, Allen LH. Nutritional importance of animal source foods. J Nutr. 2003;133(11 Suppl 2):3932S-5S.

20. de Beer H. Dairy products and physical stature: a systematic review and meta-analysis of controlled trials. Econ Hum Biol. 2012;10(3):299-309.

21. Iannotti L, Roy D. Nutritional impact of highly pathogenic avian influenza in Kenya. Food Nutr Bull. 2013;34(3):299-309.

22. United Nations Development Program (UNDP), Institute of National Planning Egypt. Egypt human development report: youth in Egypt 2010. Cairo, Egypt: UNDP; 2010

23. El-Zanaty F, Way A. Egypt demographic and health survey 2005. Cairo, Egypt: Ministry of Health and Population, National Population Council, ElZanaty and Associates, and ORC Macro; 2006.

24. WHO Child Growth Standards based on length/height, weight and age. Acta Paediatr Scandinavica Suppl. 2006;450:76-85. 
25. Way A, El-Zanaty F, R H, Ismail I. Undernutrition among young children in Egypt, Prepared for Expert Consultation. Calverton, Maryland: Measure DHS project, USAID and El-Zanaty and Associates; 2012. p. 21.

26. Filmer D, Pritchett LH. Estimating wealth effects without expenditure dataor tears: an application to educational enrollments in states of India. Demography. 2001;38(1):115-32.

27. Rutstein SO, Rojas G. Guide to DHS Statistics. Calverton, MD: Macro International, Demographic and Health Research Division; 2006.

28. O'Brien RM. A caution regarding rules of thumb for variance inflation factors. Qual Quantity. 2007:41(5):673-90.

29. Kandeel A, Manoncourt S, Abd el Kareem E, Mohamed Ahmed AN, El-Refaie $\mathrm{S}$, Essmat $\mathrm{H}$, et al. Zoonotic transmission of avian influenza virus ( $\mathrm{H} 5 \mathrm{~N} 1)$, Egypt, 2006-2009. Emerg Infect Dis. 2010;16(7):1101-7.

30. Vergne T, Grosbois V, Jobre Y, Saad A, El Nabi AA, Galal S, et al. Avian influenza vaccination of poultry and passive case reporting, Egypt. Emerg Infect Dis. 2012;18(12):2076-8

31. Lohiniva AL, Dueger E, Talaat M, Refaey S, Zaki A, Chisholm Horton K, et al. Poultry rearing and slaughtering practices in rural Egypt: an exploration of risk factors for $\mathrm{H} 5 \mathrm{~N} 1$ virus human transmission. Influenza Other Respi Viruses. 2013;7(6):1251-9.

32. Lambert V, Radwan H. Gender assessment of avian influenza in Egypt. Washington, DC: USAID; 2010.

33. Kavle J, Mehanna S, Saleh G, Foaud M, Ramzy M, Hamed D, et al. Examining factors associated with stunting in Lower Egypt in comparison to Upper Egypt: bridging the gap between cultural beliefs and feasible feeding practices through Trials for Improved Practices (TIPS). USAID Report. Washington DC; 2014.

34. Arimond M, Ruel MT. Dietary diversity is associated with child nutritional status: evidence from 11 demographic and health surveys. J Nutr. 2004;134(10):2579-85.

35. PAHO/WHO. Guiding principles for the complementary feeding of the breastfed child. Washington, DC: Pan American Health Organization; 2003.

36. Geerlings $\mathrm{H}$. Highly pathogenic avian influenza: a rapid assessment of the socio-economic impact on vulnerable households in Egypt. Cairo, Egypt: Food and Agriculture Organization; 2007.

37. World Food Program. Status of food security and vulnerability in Egypt, 2009. Cairo, Egypt: World Food Programme; 2011.

38. Calloway DH, Murphy SP, Beaton GH, Lein D. Estimated vitamin intakes of toddlers: predicted prevalence of inadequacy in village populations in Egypt, Kenya, and Mexico. Am J Clin Nutr. 1993;58(3):376-84.

39. Murphy SP, Beaton GH, Calloway DH. Estimated mineral intakes of toddlers: predicted prevalence of inadequacy in village populations in Egypt, Kenya, and Mexico. Am J Clin Nutr. 1992;56(3):565-72.

40. Siekmann $\mathrm{JH}$, Allen LH, Bwibo NO, Demment MW, Murphy SP, Neumann CG Kenyan school children have multiple micronutrient deficiencies, but increased plasma vitamin B-12 is the only detectable micronutrient response to meat or milk supplementation. J Nutr. 2003;133(11 Suppl 2):3972S-80S.

41. Dror DK, Allen LH. The importance of milk and other animal-source foods for children in low-income countries. Food Nutr Bull. 2011;32(3):227-43.

42. Darapheak C, Takano T, Kizuki M, Nakamura K, Seino K. Consumption of animal source foods and dietary diversity reduce stunting in children in Cambodia. Int Arch Med. 2013;6:29.

43. John Snow Inc., Arabic Software Engineering (ArabSoft), Clark Atlanta University, The Manoff Group and TransCentury Associates. Healthy Mother/ Healthy Child Project. Completion Report, USAID Report; Boston, MA; 2005.

44. Rogol AD, Clark PA, Roemmich JN. Growth and pubertal development in children and adolescents: effects of diet and physical activity. Am J Clin Nutr. 2000;72(2 Suppl):521S-8S.

45. Baumgartner RN, Roche AF, Himes JH. Incremental growth tables: supplementary to previously published charts. Am J Clin Nutr. 1986;43(5):711-22.

46. Kavle J, Mehanna S, Khan G, Hassan M, Saleh G, Galloway R. Cultural beliefs and perceptions of maternal diet and weight gain during pregnancy and postpartum family planning in Egypt. USAID Report. Washington DC; 2014

47. Asfaw A. Micronutrient deficiency and the prevalence of mothers' overweight/obesity in Egypt. Econ Hum Biol. 2007;5(3):471-83.

48. Asfaw A. Do government good price policies affect the prevalence of obesity? Empirical evidence from Egypt. World Dev. 2007;35:687-701.

49. Austin AM, Hill AG, Fawzi WW. Maternal obesity trends in Egypt 1995-2005. Matern Child Nutr. 2013;9(2):167-79.
50. McPhie S, Skouteris H, Daniels L, Jansen E. Maternal correlates of maternal child feeding practices: a systematic review. Matern Child Nutr. 2014;10(1):18-43

51. Fabunmi T, Onabanjo O, Oguntona O, Keshinro O, Onabanjo J, Obanla OO, et al. Nutrient intakes and nutritional status of mothers and their under-five children in a rural community of Oyo state, Nigeria. Int J Child Health Nutr. 2013;2:39-49.

52. Saha KK, Frongillo EA, Alam DS, Arifeen SE, Persson LA, Rasmussen KM. Household food security is associated with infant feeding practices in rural Bangladesh. J Nutr. 2008;138(7):1383-90.

53. Rutstein SO. Further evidence of the effects of preceding birth intervals on neonatal, infant, and under-five-years mortality and nutritional status in developing countries: evidence from the demographic and health surveys DHS working papers. Calverton, MD: Macro International, Demographic and Health Research Division; 2008.

54. Dewey KG, Cohen RJ. Does birth spacing affect maternal or child nutritional status? A systematic literature review. Matern Child Nutr. 2007;3(3):151-73.

55. Zottarelli LK, Sunil TS, Rajaram S. Influence of parental and socioeconomic factors on stunting in children under 5 years in Egypt. East Mediterr Health J. 2007;13(6):1330-42.

56. Mora JO, Nestel PS. Improving prenatal nutrition in developing countries: strategies, prospects, and challenges. Am J Clin Nutr. 2000;71(5 Suppl):1353S-63S.

57. Merchant K, Martorell R. Frequent reproductive cycling: does it lead to nutritional depletion of mothers? Prog Food Nutr Sci. 1988;12(4):339-69.

58. Huffman S, Piwoz E, Vosti S, Dewey K. Babies, soft drinks and snacks: a concern in low- and middle-income countries. Mat Child Nutr. 2014 doi:10.1111/mcn.12126. [Epub ahead of print]

59. Kavle J, Mehanna S, Saleh G, Foaud M, Ramzy M, Hamed D, et al. Exploring why junk foods are 'essential' foods and how culturally tailored recommendations improved feeding in Egyptian children. Mat Child Nutr. 2014. doi:10.1111/mcn.12165.

\section{Submit your next manuscript to BioMed Central and take full advantage of:}

- Convenient online submission

- Thorough peer review

- No space constraints or color figure charges

- Immediate publication on acceptance

- Inclusion in PubMed, CAS, Scopus and Google Scholar

- Research which is freely available for redistribution

Submit your manuscript at www.biomedcentral.com/submit
C Biomed Central 